\title{
Fibroblast phenotypes in different lung diseases
}

\author{
Heng Du, Dali Chen, Yubin Zhou, Zhaojie Han and Guowei Che*
}

\begin{abstract}
Background: The "seed and soil" hypothesis emphasizes the importance of interactions between tumor cells and their microenvironment. CAFs (Cancer associated fibroblasts) are important components of the tumor microenvironment. They were widely involved in cancer cells growth and metastasis. Fibroblasts may also play a role in inflammatory disease. The phenotype conversion of fibroblasts in lung diseases has not been investigated previously. We hypothesized that fibroblasts phenotypes may vary among different types of lung disease.

Methods: The study included six types of lung tissues, ranging from normal lung to lung adenocarcinoma with lymphatic metastasis. Para-carcinoma tissues which were 2-cm-away from the tumor focus were also included in the analysis. The expression of target proteins including alpha-SMA (smooth muscle actin), FAP (fibroblast activation protein), vimentin, E-cadherin, and CK-19 (cytokeratin-19) were examined by immunohistochemistry. TGF-beta(transforming growth factor) and Twist were detected simultaneously in all samples.

Results: A progressive increase in the levels of alpha-SMA, vimentin and CK-19 was observed in correlation to the degree of malignancy from normal lung tissue to lung adenocarcinoma with lymphatic metastasis, whereas E-cadherin expression showed the opposite trend. TGF-beta and Twist were detected in cancer tissues and inflammatory pseudotumors. None of the proteins were detected in para-carcinoma tissues.

Conclusions: Fibroblast phenotypes varied according to the type and degree of lung malignancy and fibroblasts phenotypic conversion occurs as a gradual process with specific spatiotemporal characteristics. Similar fibroblast phenotypes in inflammatory diseases and cancer tissues suggested a correlation between inflammation and cancer and implied a common mechanism underlying the formation of fibroblasts in inflammatory diseases and lung cancer.
\end{abstract}

Keywords: Cancer associated fibroblasts, Phenotypes, Lung disease, Immunohistochemistry

\section{Background}

The high degree of malignancy and heterogeneity of cancer cells have led researchers to focus on the study of malignant cells present in the epithelial compartment [1]. The resistance of certain cancer cells to treatment remains a critical issue [2]. In recent years, researchers have discovered that tumor microenvironment also plays an important role in tumor development. The interaction of the tumor microenvironment with cancer cells make the matters more complicated [2-5]. Tumor microenvironment may play a key role in tumor invasion and can indirectly affect prognosis $[2,6]$. The development of resistance against chemotherapeutic drugs brought

\footnotetext{
* Correspondence: hxcheguowei@yahoo.com

Department of Thoracic Surgery, West-China Hospital, Sichuan University, Chengdu 610041, China
}

(c) 2014 Du et al.; licensee BioMed Central Ltd. This is an Open Access article distributed under the terms of the Creative Commons Attribution License (http://creativecommons.org/licenses/by/4.0), which permits unrestricted use, distribution, and reproduction in any medium, provided the original work is properly credited. The Creative Commons Public Domain Dedication waiver (http://creativecommons.org/publicdomain/zero/1.0/) applies to the data made available in this article unless otherwise stated.

attention to the fact that the soil (tumor microenvironment) is as important as seeds (cancer cells).

Specialized fibroblasts named cancer-associated fibroblasts (CAFs) are characterized by "cross-talk" with cancer cells and have become novel targets for cancer therapy [2,6,7]. CAFs can be formed through several ways. The way named EMT (epithelial-mesenchymal transition) was important. Studies have demonstrated that in human breast and prostate cancer, TGF- $\beta$ and Twist secreted by tumor cells may induce EMT and promote the formation of CAFs [3,7-9]. CAFs express high levels of $\alpha$-SMA (smooth muscle actin) and vimentin $[3,10,11]$, whereas they are negative for cytokeratin and E-cadherin $[3,4,12]$. Normal fibroblasts suppress tumor genesis by inhibiting the proliferation of the adjacent epithelium, CAFs play an opposite role [4].

Vicent $S$ et al. [13] made a cross-species functional characterization of mouse and human lung CAFs and 
finally found that CAFs supported the growth of lung cancer cells in vivo by secretion of soluble factors that directly stimulate the growth of tumor cells. They also found that IL-6 (interleukin-6) secreted by CAFs promoted cancer cells growth. Besides, CXCL-12/CXCR4 axis which existed between the cross-talk of CAFs and non-small lung cancer cells was also contributed to the proliferation of cancer cells [14]. Some proteins expressed by CAFs such as matrix metalloproteinase (MMP)-2, $\alpha$-SMA, podoplanin and carbonic anhydrase (CA) IX may correlated with the prognosis of lung cancer [15-17].

The phenotype conversion from normal fibroblasts to CAF was associated with carcinogenesis but whether the CAF phenotype varies among cancer tissues remain to be elucidated. We hypothesized that TGF- $\beta$ and Twist participated in lung carcinogenesis. In previous studies, the role of CAFs was investigated by assessing their tissue-specific expression only in one type of human cancer such as human prostate cancer or human breast cancer $[18,19]$. We analyzed fibroblasts in a set of samples which including chronic inflammation, normal lung tissue, atypical adenomatous hyperplasia, carcinoma in situ, lung adenocarcinoma, and lung adenocarcinoma with lymphatic metastasis. Para-carcinoma tissues were collected from the relevant patients. A comparative analysis of these tissues was performed to examine the characteristics of the phenotypic conversion of fibroblasts.

\section{Methods}

\section{Patients}

Patient samples were obtained from the department of thoracic surgery of West China Hospital. The study was approved by the West China Hospital Ethics Committee (year 2013, No.32). All patients signed informed consent forms. The distribution of patients was as follows: $\mathrm{N}$ (pulmonary bulla) $(\mathrm{n}=20)$, I (inflammatory pseudotumor) $(\mathrm{n}=22), \mathrm{H}$ (atypical adenomatous hyperplasia) $(\mathrm{n}=19), \mathrm{CIS}$ (carcinoma in situ) $(\mathrm{n}=13)$ and CISJ (corresponding adjacent tissues), A (lung adenocarcinoma without lymph node metastasis) $(\mathrm{n}=26)$ and AJ (corresponding adjacent tissues), and AM (lung adenocarcinoma with lymphatic metastasis) $(\mathrm{n}=27)$ and AMJ (corresponding adjacent tissues). None of the patients had received chemotherapy or radiotherapy before surgery. Tissues from patients with pulmonary bulla who were treated surgically were used as controls because of the lack of available healthy donor tissues. Besides, the CIS samples were not as much as other samples for the reason that cancer was very difficult to diagnose in an early stage. Nearly all the CIS samples came from patients whose tumors were found by regular medical examination. Unlike other pathological stages of lung cancer, samples of CIS (carcinoma in situ) of lung cancer is relatively hard to found and the size of samples was very small. We could not obtained enough sections from a single patient. Histological analyses of tissue samples were performed independently by two pathologists who were blinded to patients' clinical information according to World Health Organization criteria.

\section{Methods \\ Immunohistochemistry}

$4.5 \mu \mathrm{m}$ thick serial sections of formalin-fixed and paraffinembedded tissue samples were heated in citrate buffer $(0.01 \mathrm{M})$ for $30 \mathrm{~min}$. Endogenous peroxidase activity was quenched by incubation in $0.5 \% \mathrm{H}_{2} \mathrm{O}_{2}$. Sections were then blocked with serum and incubated with the respective primary antibodies at $4^{\circ} \mathrm{C}$ overnight. Primary antibodies and their dilutions were as follows: mouse monoclonal anti $\alpha$-SMA (ZXGB BIO, Beijing, CHINA, 1:100); rabbit polyclonal anti FAP (Assay Biotech, U.S.A. 1:200); mouse monoclonal anti vimentin, mouse monoclonal anti-Ecadherin, mouse monoclonal anti- CK-19, and rabbit polyclonal anti TGF- $\beta$ (all obtained from ZXGB BIO, Beijing, CHINA, and used at 1:100); and mouse monoclonal antiTwist (Santa Cruz Biotechnology, Dallas, U.S.A. 1:100). Negative control sections were concurrently obtained from each patient and incubated in PBS $(0.01 \mathrm{M})$. Sections were then incubated in the corresponding secondary antibody (anti-mouse IgG and anti-rabbit IgG, both from ZSGB BIO, Beijing, CHINA,1:200), then in the avidin biotin complex reagent (ZSGB BIO, Beijing, CHINA,1:100) for $1 \mathrm{~h}$ at room temperature. Next, sections were visualized by using 3, 3- diaminobenzidine $\left(25 \mu \mathrm{L} 3 \% \mathrm{H}_{2} \mathrm{O}_{2}\right.$ and $5 \mathrm{~mL} \mathrm{DAB}$ ) for $4 \mathrm{~min}$ and counterstained with nuclear fast red for $2 \mathrm{~min}$.

\section{Immunohistochemistry analysis}

For the markers expressed in cancer cells, high magnification $(40 \times$ objective) was used to count the individual cancer cells and a total of 200 cancer cells were scored for each high-power field. For every section, five fields were selected randomly. Normal alveolar epithelial cells stained red by nuclear fast red were selected as negative controls. According to Friedrichs et al. [18], a staining index (SI, values $0,1,2,3,4,6$, and 9) was calculated as a product of staining intensity $(0-3)$ and the proportion of positive cells $(0 \%=0,1-10 \%=1,11-50 \%=2,>50 \%=3)$ [18]. For CAFs, the SI was calculated as a product of staining intensity $(0-3)$ and the staining extent $(0 \%=0$, $1-10 \%=1,11-50 \%=2,>50 \%=3$ ).

\section{Statistical analysis}

The Wilcoxon rank sum test was used to compare the marker status among the six disease types. Correlation analyses between TGF- $\beta$ and $\alpha$-SMA, TGF- $\beta$ and Ecadherin, TGF- $\beta$ and vimentin, Twist and $\alpha$-SMA, Twist and vimentin, and Twist and E-cadherin were performed 
by comparing the SI (staining index) for each protein in the same disease using Spearman's rank test. A P value (two sides) $<0.05$ was considered to indicate statistical significance.

\section{Results}

\section{Clinical findings}

The study included 127 patients (70 men and 57 women) with a mean age of 55 years (range: $18-74$ years). The presence of lymph node metastasis was confirmed by intraoperative frozen section analysis and none of the patients had distant metastasis.

\section{Fibroblasts phenotypic conversion characteristics Detection of fibroblasts and epithelial markers}

$\alpha$-SMA was detected in benign and malignant tissues and its expression was localized to blood vessels and airway ducts in $\mathrm{N}$ and $\mathrm{H}$. Stromal cells were positive for $\alpha$-SMA in inflammatory pseudotumor as well as in all three pathological stages of adenocarcinoma, although with different staining intensity. $\alpha$-SMA expression was lower in CIS (SI ranged from 1 to 4 and the median was 2$)$ than in A (SI : 1 to 6 , median was 4$)(\mathrm{P}=0.026)$, whereas AM (SI: 4 to 9, median was 6) showed higher expression than A $(\mathrm{P}=0.009)$. Vimentin expression was negative in $\mathrm{N}$ and $\mathrm{H}$ but positive in $\mathrm{I}$. In the cancer samples, Vimentin expression was higher in A (SI: 2 to 6 , median was 3.5 ) than in CIS (SI: 0 to 4 , median was 2) $(P=0.017)$ and it was higher in AM (SI: 3 to 9, median was 6$)$ than in $A(P=0.022)$. In general, $\alpha$-SMA and vimentin expression increased gradually from $\mathrm{N}$ to AM (Figure 1).

The epithelial marker E-cadherin was expressed at high levels in the glandular epithelium of H. E-cadherin staining intensity was lower in most CIS (SI: 0 to 3, median was 2) samples than in H (SI: 2 to 4 , median was 3 ) samples $(\mathrm{P}=0.008)$, and it was higher in $\mathrm{A}$ (SI: 0 to 4 , median was 3$)$ than in CIS $(P=0.827)$. E-cadherin expression was significantly lower in AM (SI: 0 to 1, median was 1$)$ than in $\mathrm{A}(\mathrm{P}<0.001)$. $\mathrm{CK}-19$ showed strong staining in $\mathrm{H}$ and was expressed at higher levels in $\mathrm{A}$ than in CIS $(\mathrm{P}=0.003)$ and in AM (SI: 4-9 median was 6) than in $\mathrm{A}(\mathrm{P}=0.035)$. Cancer epithelial cells expressed more CK-19 in the samples from CIS to AM. The expression of epithelial markers was negative in $\mathrm{N}$ and in I (Figure 2).

\section{Immunohistochemical detection of TGF- $\beta$, FAP, and Twist}

The expression of TGF- $\beta$, FAP, and Twist was analyzed by IHC. Unlike the four markers which were detected in interstitial cells (such as $\alpha$-SMA and vimentin) or the cancer cells membrane (such as CK-19), TGF- $\beta$ and FAP expression was detected in the cytoplasm of cancer cells while twist was located in both cytoplasm and nucleus. The three factors were expressed in I, CIS, $\mathrm{A}$, and AM, whereas $\mathrm{N}, \mathrm{H}$, but para-carcinoma tissues were negatively stained (the results of $N, I$, and $H$ were not included in Figure 3). TGF- $\beta$ was expressed at higher levels in AM (SI: 3 to 9, median was 6) than in A (SI: 2-9 median was 3.5$)(\mathrm{P}<0.001)$. No statistical significance was seen between CIS and A $(P=0.392)$. On the other hand, Twist expression was seen in A and AM. FAP expression was positive in the matrix of cancer cells and negative in that of CAFs. FAP expression was detected in cancer cells of CIS, A and AM, although the differences in expression levels among CIS, A, and AM did not reach statistical significance (Figures 3 and 4).

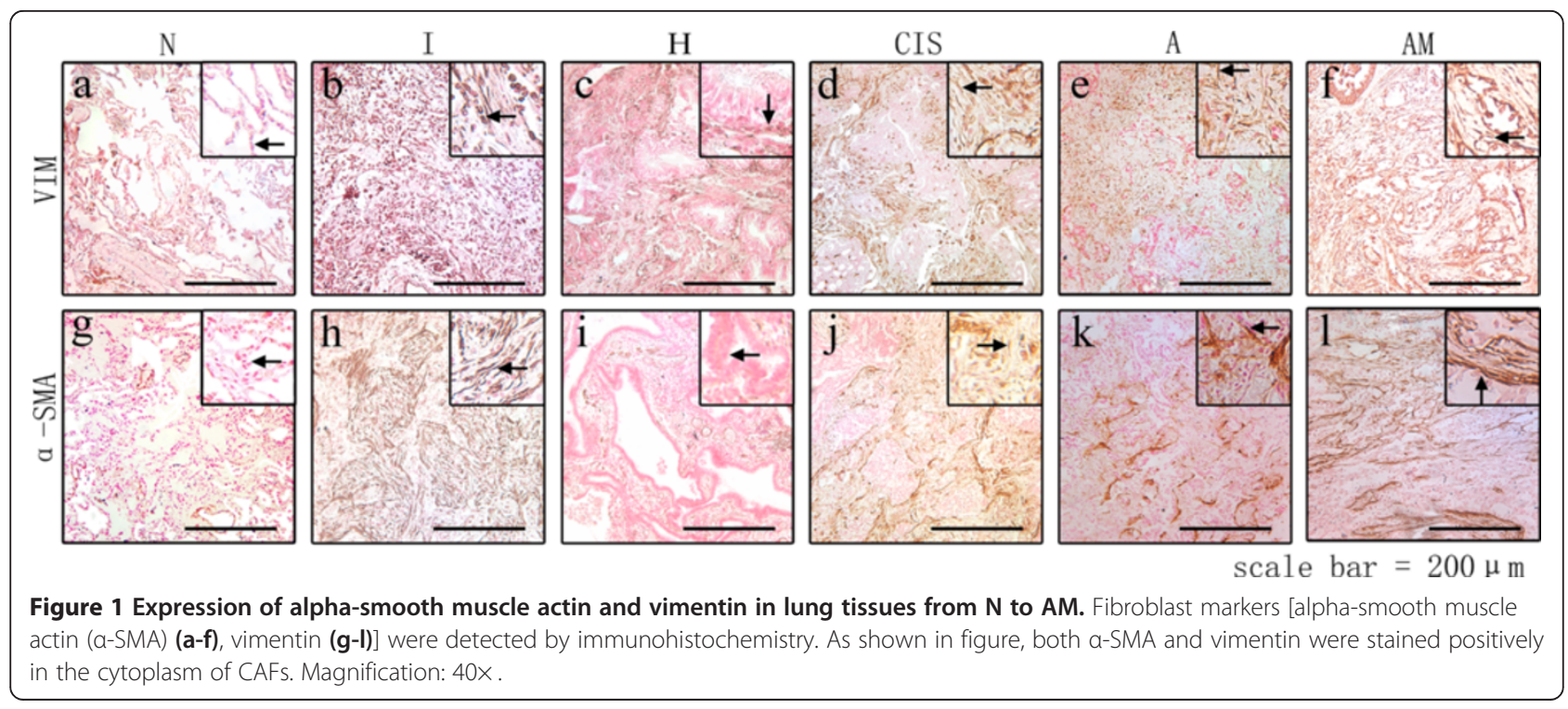




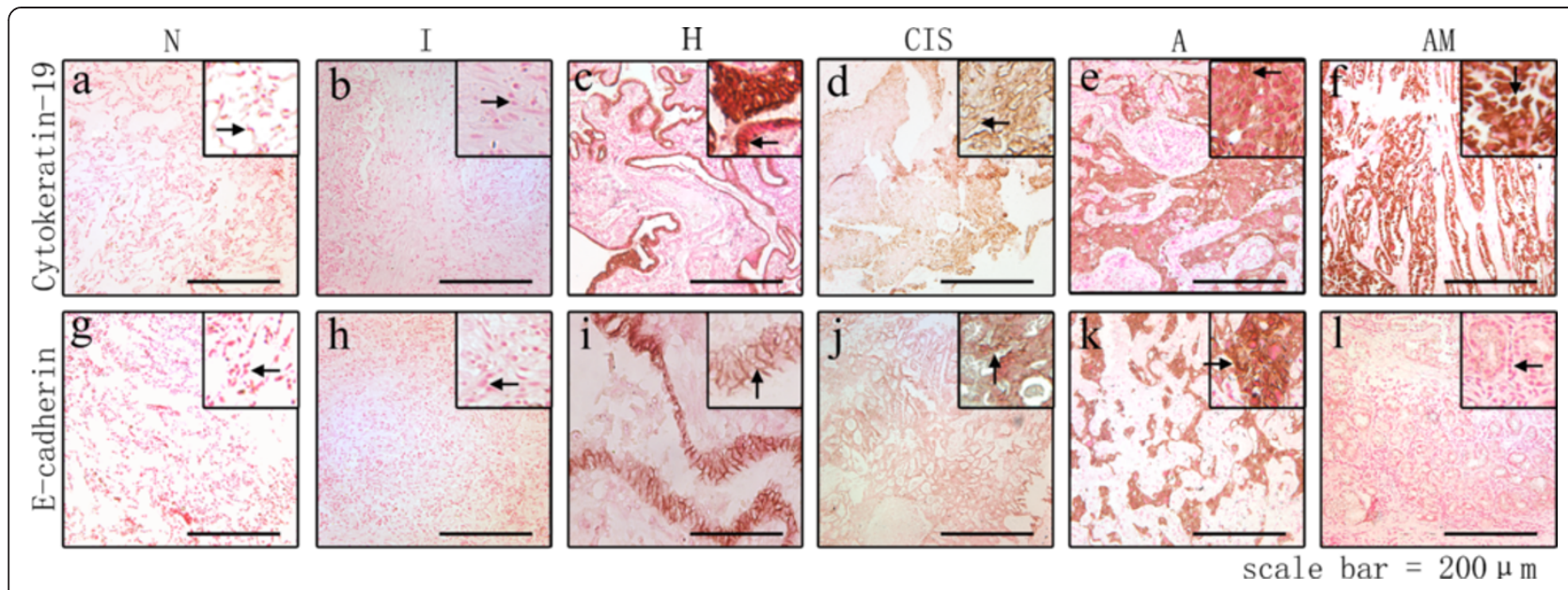

Figure 2 Expression of E-cadherin and cytokeratin-19 in lung tissues from $\mathbf{N}$ to AM. Epithelial markers [E-cadherin (a-f) and cytokeratin-19 (CK-19) (g-I)] were detected by immunohistochemistry. E-cadherin was located in cell membrane while CK-19 was located in cytoplasm. Magnification: 40x

\section{Correlation analysis}

All the lung cancer samples (including CIS, A and AM, totally 66 samples) expressed different levels of $\alpha$-SMA, vimentin, E-cadherin, Twist and TGF- $\beta$. We performed a correlation analysis between TGF- $\beta$ and $\alpha$-SMA, TGF- $\beta$ and vimentin, TGF- $\beta$ and E-cadherin, Twist and $\alpha-S M A$, Twist and E-cadherin and Twist and $\alpha$-SMA in all the cancer samples. A significant positive correlation was observed between TGF- $\beta$ and $\alpha$-SMA and between TGF- $\beta$ and vimentin expression (Spearman's rank correlation
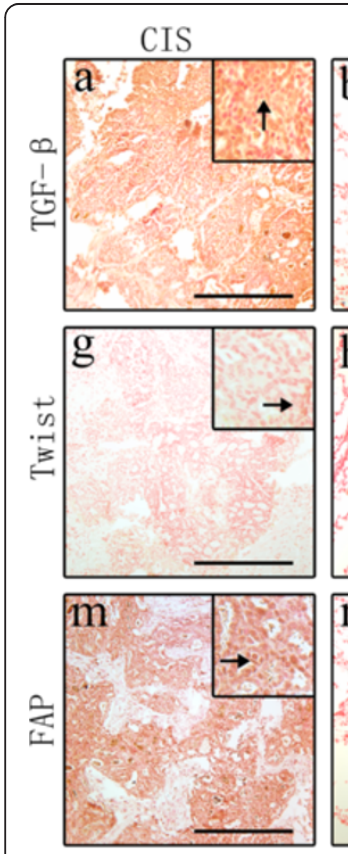
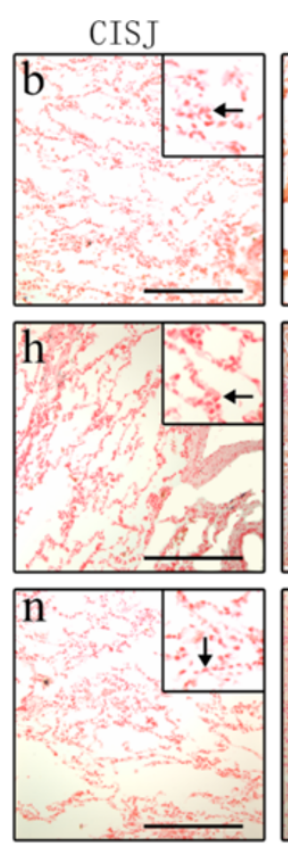
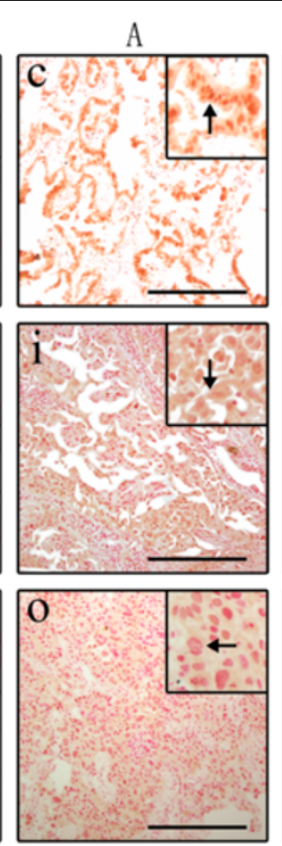
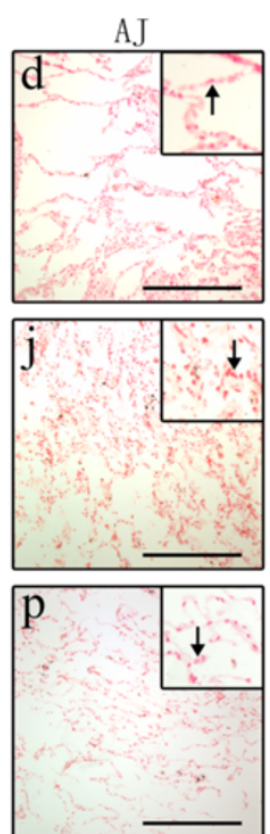
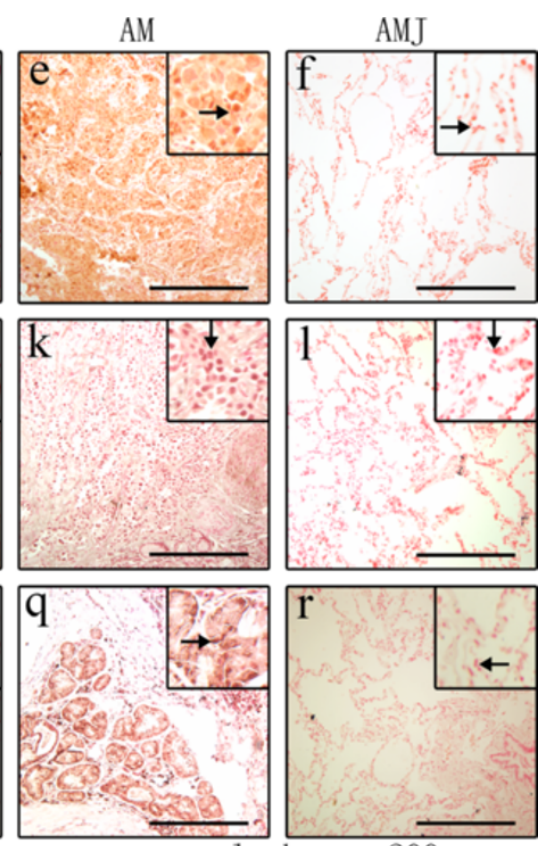

scale bar $=200 \mu \mathrm{m}$

Figure 3 Expression of TGF- $\beta$, FAP and Twist in cancer tissues and para-carcinoma tissues. Key factors in the cell signaling pathway including TGF- $\beta$ (a-f) and Twist ( $\mathbf{g}-\mathbf{l})$ were detected by immunohistochemistry. The expression of TGF- $\beta$ and Twist in I (inflammation pseudotumor) is not included in the figure. In these samples, TGF- $\beta$ was located in cytoplasm (a, $\mathbf{c}, \mathbf{e})$ and Twist $\mathbf{( g , ~} \mathbf{l}, \mathbf{k})$ can be detected both in cytoplasm and nuclei of cancer cells. FAP, a marker of CAFs, was expressed in the cytoplasm of cancer cells rather than in the stroma of cancer tissues ( $\mathbf{m}$, $\mathbf{o}, \mathbf{q}$ ) This novel result may indicate that some cancer cell could secret FAP just like CAFs or these cancer cells secreting FAP may be a novel origin of CAFs. However, TGF- $\beta$ (b, d, $\mathbf{f})$, Twist $(\mathbf{h}, \mathbf{j}, \mathbf{l})$ or FAP $(\mathbf{n}, \mathbf{p}, \mathbf{r})$ were negatively expressed by all of the para-carcinoma tissues. Magnification: 40X. 


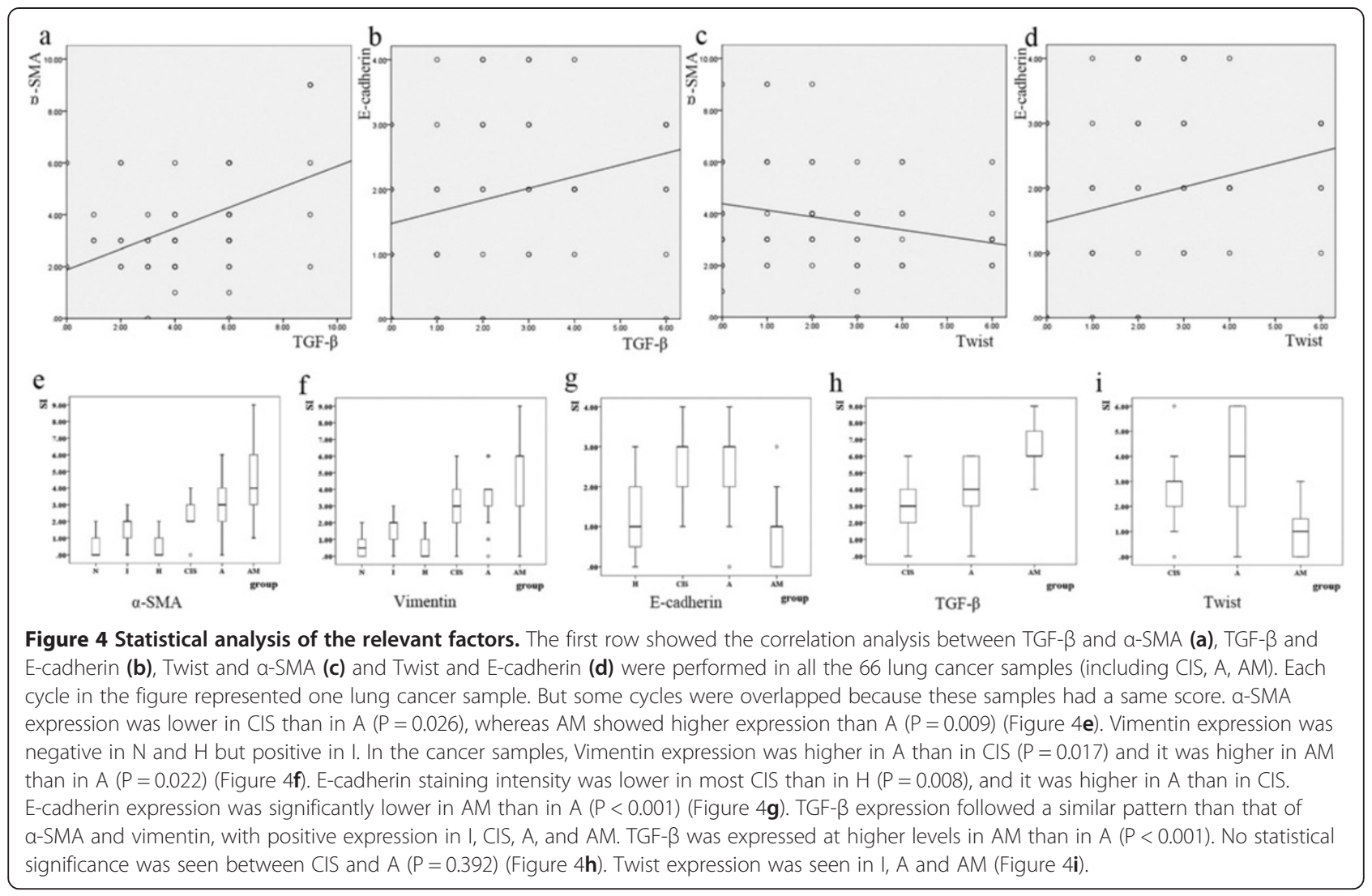

coefficient $r=0.396, p=0.001 ; r=0.404, p=0.009$, respectively). A significant inverse correlation was observed between TGF- $\beta$ and E-cadherin $(r=-0.449, \mathrm{p}<0.001)$. However, a significant positive correlation was observed between Twist and E-cadherin expression ( $r=0.318$, $\mathrm{p}=0.009)$. The relationship between Twist and $\alpha$-SMA did not reach statistical significance $(\mathrm{p}=0.064)$ (Figure 4$)$.

\section{Spatial characteristics of the phenotypic conversion of cancer-associated fibroblasts}

The spatial pattern of the phenotypic conversion of fibroblasts was examined by detecting marker protein expression in para-carcinoma tissues using the same methods. The results showed that adjacent tissues stained negative for all the marker proteins analyzed (Figure 3).

\section{Discussion}

In previous studies, co-implantation of tumor cells and CAFs into immunodeficient mice induced tumor growth at a faster rate than the implantation of cancer cells alone or that of normal fibroblasts $[19,20]$. Cytokines secreted by CAFs may contribute to destroy the basement membrane to facilitate tumor invasion and metastasis [21].

In the present study, we used six kinds of lung disease to examine the spatiotemporal characteristics of the phenotypic conversion of fibroblasts. A mild, progressive increasing trend in CAFs was observed from CIS, A to AM tissues. This could be explained as follows: the expression of $\alpha$-SMA and vimentin in the stroma were increased from $\mathrm{N}$ to $\mathrm{AM}$ and both factors followed a similar pattern of upregulation. The upregulation of $\alpha$-SMA promotes tumor formation and metastasis [22]. However, $\alpha$-SMA expression was also positive in stromal cells of I (inflammatory pseudotumor), similar to that in tumors $(P=0.059)$. Increased TGF- $\beta$ up-regulated the expression of $\alpha$-SMA in I and in lung cancer $(r=0.396$, $\mathrm{p}=0.001$ ). Vimentin, whose up-regulation is an indicator of EMT, showed a similar staining pattern among the different disease stages. Vimentin overexpression has been detected in several types of tumors, including lung adenocarcinoma, and its expression is correlated with tumorigenesis, invasion, and metastasis [23-25]. In addition to the markers of CAFs, we analyzed epithelial markers, including E-cadherin and CK-19. The downregulation of these two epithelial markers accompanied by the up-regulation of $\alpha$-SMA and vimentin is considered a key process associated with EMT [26,27]. E-cadherin may play a role in suppressing tumor metastasis. Liu et al. showed that the impaired integrity of the E-cadherincatenin system is responsible for the reduced or even negative expression of E-cadherin [28,29]. In addition, Twist 
expression is associated with aberrant E-cadherin expression. CK-19 is frequently detected in serum as the fragment CYFRA -21 [30-32], and its expression in parenchyma cells is consistent with the results of the present study. The upregulation of CK-19 expression in cancer epithelial cells is associated with tumor invasion and lymphatic metastasis [33-35], which is also consistent with our results. However, the association between high CK-19 reactivity and cancer and its role in metastasis should be further investigated.

TGF- $\beta$, Twist and FAP were expressed at various levels in the different tumor tissues from CIS to AM. TGF- $\beta$ is a multifunctional protein that induces fibrosis of lung tissue, tumor invasion, and metastasis by promoting EMT, and EMT takes an active part in fibrotic disease, as well as in cancer cell movement and invasion [36-39].

The involvement of TGF- $\beta$ in EMT may require its association with Smad and Snail signaling or the activity of the Ras pathway; however, activated Smad or H-Ras may not be sufficient for the EMT process without the presence of TGF- $\beta$ [40]. Ronnov-Jessen et al. suggested that TGF- $\beta$ is the only factor required for the conversion of normal fibroblasts into CAFs [41]. Furthermore, Fibroblasts secrete TGF- $\beta$ to remain active and promote their own proliferation [3]. The transcription factor Twist exerts a similar function to that of TGF- $\beta[8,9,42,43]$, and its upregulation is correlated with alterations in Ecadherin expression [44]. However, the present study showed the opposite results. A significant positive relationship was observed between Twist and E-cadherin expression $(r=0.318, p=0.009)$. Comparison of Twist and E-cadherin expression between CIS and A showed a negative correlation. These results indicated a discordant pattern of expression of Twist, particularly in association with the process of tumor metastasis, which led us to hypothesize that Twist expression may be an indicator of metastasis in lung adenocarcinoma.

Among the six types of tissues, I (inflammatory pseudotumor) exhibited an abnormal pattern of immunostaining and was positive for $\alpha$-SMA, vimentin, as well as TGF- $\beta$ (Figure 1). TGF- $\beta$ is among the factors secreted during the inflammatory response [45] and may promote the upregulation of $\alpha$-SMA in response to inflammation. In inflammatory diseases such as Hepatitis $\mathrm{B}$ and inflammatory bowel disease, malignant transformation may lead to the development of hepatocellular carcinoma and colorectal carcinoma, respectively. The results of the present study suggest that benign inflammatory diseases may progress and develop into malignant lung tumors.

In addition to $\alpha$-SMA and vimentin, FAP, is also considered to be a specific marker for CAFs [46]. However, our results showed that FAP was expressed in the cytoplasm of cancer cells rather than in the cytoplasm of
CAFs, and no statistically significant differences were detected among CIS, A, and AM tissues. TGF- $\beta$ expression was also localized to the matrix of cancer cells, which was not consistent with the results reported by Xing et al. These two novel phenomena revealed by our findings indicated that cancer cells might have a similar function as CAFs and CAFs may not originate exclusively from normal epithelial cells but may also be derived from mutant epithelial cells, including cancer cells [2].

Both lung inflammatory pseudotumor and atypical adenomatous hyperplasia might have something to do with malignant lung diseases. Lung inflammatory pseudotumor, whose etiology was still unknown, was a relative rare benign lung tumor and account for about $0.7 \%$ of primary pulmonary and bronchial tumors. [47] This benign lung disease had malignant biological behavior including locally invasive, aggressiveness and unfavorable evolution which needed extensive pulmonary resection to prevent local recurrence. Though no detail data about the incidence and the probability that the patients with lung cancer resulting from inflammatory pseudotumor was provided, it was better to have this lesion resected as early as possible [47]. Atypical adenomatous hyperplasia may be the adenoma in an adenoma-carcinoma sequence in the lung periphery, leading to the development of adenocarcinoma. Atypical adenomatous hyperplasia had a low morbidity of $4.4 \%$ and $9.6 \%[48,49]$. The incidence was higher in patients bearing lung cancer especially in those with lung adenocarcinoma ( $15.6 \%$ vs $23.2 \%)$ [50]. It had been demonstrated that atypical adenomatous hyperplasia might result in lung squamous carcinoma. Whether or not it would result in lung adenocarcinoma still need more research [51].

The present study analyzed a series of lung diseases simultaneously. We used longitudinal and cross-sectional analyses to investigate phenotypic variations in fibroblasts. While previous studies compared cancer cells to normal tissues in a static manner, our research reflected the dynamic changing process of fibroblasts. In addition to their role in promoting tumor invasion and metastasis, their function in providing a microenvironment for tumor cells similar to that of soils for seeds, fibroblasts were shown to undergo phenotypic conversion in a specific spatiotemporal pattern. Considering the progressive emergence of drug resistant phenotypes in cancer, our results suggest that activated fibroblasts may represent a potential target for molecular targeted therapy in lung cancer and provide a correlation between inflammatory diseases and cancer. The limitations of the present study were mainly derived from the lack of sample. Samples of CIS were specially limited for it was very hard to diagnose cancer at very early stage. The differences between our results and those of previous studies could be related to the small number of samples included in the analysis. 
In addition, tumor tissues consisted of several types of cells, which could lead to the differential expression of the factors analyzed.

In the present study, we detected seven types of factors. TGF- $\beta$ showed a positive role in EMT and facilitated the generation of CAFs. Because Twist showed a similar function, we were unable to determine whether one of the factors plays a key role or if both are critical for EMT. If both TGF- $\beta$ and Twist are essential for EMT, assessment of the potential cross-talk between the two factors would be important. However, IHC is insufficient to examine this issue, which we plan to address using different methods in future studies.

\section{Conclusions}

Fibroblast phenotypes vary according to the type and degree of lung diseases and their phenotypic conversion occurs as a gradual process with specific spatiotemporal characteristics. Similar fibroblast phenotypes in inflammatory diseases and cancer tissues suggested a correlation between these two disease types and a common mechanism underlying the formation of fibroblasts in inflammatory diseases and lung cancer. The present study want to provide a new idea about cancer therapy.

\begin{abstract}
Abbreviations
A: Lung adenocarcinoma without lymph node metastasis; AJ: Lung tissue 2-cm away from the tumor; AM: Lung adenocarcinoma with lymph node metastasis; AMJ: Lung tissue 2-cm away from the tumor; CAFs: Cancer associated fibroblasts; CIS: Carcinoma in situ; CISJ: Lung tissue 2-cm away from the tumor; CK-19: Cytokeratin-19; FAP: Fibroblast activation protein; H: Atypical adenomatous hyperplasia; I: Inflammatory pseudotumor; N: Normal lung tissue; TGF- $\beta$ : Transforming growth factor- $\beta$; $a$-SMA: $a-$-smooth muscle actin; SI: Staining index.
\end{abstract}

\section{Competing interests}

The authors declare that they have no competing interests.

\section{Authors' contributions}

HD carried out the research, prepared the figures and wrote the paper. DC was in charge of collecting specimens and conducted sample preparation. YZ prepared samples and analyzed data. ZH did statistical analyses and discussed experiments. All authors read and approved the final manuscript.

\section{Acknowledgements}

We greatly appreciate the assistance of the staff of the Department of Thoracic Surgery, West China Hospital, Sichuan University, and thank them for their efforts.

This work supported by the National Science Foundation (No:81272595,to CHE guowei).

All authors declared that they had no conflicts of interest.

Received: 2 March 2014 Accepted: 18 August 2014

Published online: 05 September 2014

\section{References}

1. Micke P, Ostman A: Tumour-stroma interaction:cancer-associated fibroblasts as novel targets in anti-cancer therapy? Lung Cancer 2004, 45:S163-S175.

2. Franco OE, Shaw AK, Strand DW, Hayward SW: Cancer associated fibroblasts in cancer pathogenesis. Semin Cell Dev Biol 2010, 21:33-39.

3. Xing F, Saidou J, Watabe K: Cancer associated fibroblasts (CAFs) in tumor microenvironment. Front Biosci 2011, 15:166-187.
4. Erez N, Truitt M, Olson P, Arron ST, Hanahan D: Cancer-associated fibroblasts are activated in incipient neoplasia to orchestrate tumorpromoting inflammation in an NF-kappaB-dependent manner. Cancer Cell 2010, 17:135-147.

5. Shimoda M, Mellody KT, Orimo A: Carcinoma-associated fibroblasts are a rate-limiting determinant for tumour progression. Semin Cell Dev Biol 2010, 21:19-25.

6. Bhowmick NA, Neilson EG, Moses HL: Stromal fibroblasts in cancer initiation and progression. Nature 2004, 432:332-337.

7. Micke $P$, Östman A: Exploring the tumour environment cancer-associated fibroblasts as targets in cancer therapy. Oncol Endocr Metab 2005, 9:1217-1233.

8. Karreth FA, Tuveson D: Twist induces an epithelial-mesenchymal transition to facilitate tumor metastasis. Canc Biol Ther 2004, 3:1508-1509.

9. Yang J, Mani SA, Donaher JL, Ramaswamy S, Itzykson RA, Come C, Savagner P, Gitelman I, Richardson A, Weinberg RA: Twist, a master regulator of morphogenesis, plays an essential role in tumor metastasis. Cell 2004, 117:927-939.

10. Liao D, Luo Y, Markowitz D, Xiang R, Reisfeld RA: Cancer associated fibroblasts promote tumor growth and metastasis by modulating the tumor immune microenvironment in a $4 \mathrm{~T} 1$ murine breast cancer model. PLoS One 2009, 4:e7965.

11. Paland N, Kamer I, Kogan-Sakin I, Madar S, Goldfinger N, Rotter V: Differential influence of normal and cancer-associated fibroblasts on the growth of human epithelial cells in an in vitro cocultivation model of prostate cancer. Mol Canc Res 2009, 7:1212-1223.

12. Gravdal K, Halvorsen OJ, Haukaas SA, Akslen LA: A switch from E-cadherin to $\mathrm{N}$-cadherin expression indicates epithelial to mesenchymal transition and is of strong and independent importance for the progress of prostate cancer. Clin Cancer Res 2007, 13:7003-7011.

13. Vicent $S$, Sayles LC, Vaka D, Khatri P, Gevaert O, Chen R, Zheng Y, Gillespie AK, Clarke N, Xu Y, Shrager J, Hoang CD, Plevritis S, Butte AJ, Sweet-Cordero EA: Cross-species functional analysis of cancer-associated fibroblasts identifies a critical role for CLCF1 and IL-6 in non-small cell lung cancer in vivo. Cancer Res 2012, 72:5744-5756.

14. Wald O, Izhar U, Amir G, Kirshberg S, Shlomai Z, Zamir G, Peled A, Shapira OM: Interaction between neoplastic cells and cancer-associated fibroblasts through the CXCL12/CXCR4 axis: role in non-small cell lung cancer tumor proliferation. J Thorac Cardiovasc Surg 2011, 141:1503-1512.

15. Ishikawa S, Takenaka K, Yanagihara K, Miyahara R, Kawano Y, Otake Y, Hasegawa S, Wada H, Tanaka F: Matrix metalloproteinase-2 status in stromal fibroblasts, not in tumor cells, is a significant prognostic factor in non-small-cell lung cancer. Clin Cancer Res 2004, 10:6579-6585.

16. Chen $Y$, Zou L, Zhang $Y$, Chen $Y$, Xing P, Yang W, Li F, Ji X, Liu F, Lu X: Transforming growth factor- $\beta 1$ and $\alpha$-smooth muscle actin in stromal fibroblasts are associated with a poor prognosis in patients with clinical stage I-IIIA nonsmall cell lung cancer after curative resection. Tumour Biol 2014, 35:6707-6713 [Epub ahead of print].

17. Nakao M, Ishii G, Nagai K, Kawase A, Kenmotsu H, Kon-No H, Hishida T, Nishimura M, Yoshida J, Ochiai A: Prognostic significance of carbonic anhydrase IX expression by cancer-associated fibroblasts in lung adenocarcinoma. Cancer 2009, 115:2732-2743.

18. Friedrichs K, Gluba S, Eidtmann H, Jonat W: Overexpression of P53 and prognosis in breast cancer. Cancer 1993, 72:3641-3647.

19. Olumi AF, Grossfeld GD, Hayward SW, Carroll PR, Tlsty TD, Cunha GR: Carcinoma-associated fibroblasts direct tumor progression of initiated human prostatic epithelium. Cancer Res 1999, 59:5002.

20. Orimo A, Gupta PB, Sgroi DC, Arenzana-Seisdedos F, Delaunay T, Naeem R, Carey VJ, Richardson AL, Weinberg RA: Stromal fibroblasts present in invasive human breast carcinomas promote tumor growth and angiogenesis through elevated SDF-1/CXCL12 secretion. Cell 2005, 121:335-348.

21. Koukourakis MI, Giatromanolaki A, Harris AL, Sivridis E: Comparison of metabolic pathways between cancer cells and stromal cells in colorectal carcinomas: a metabolic survival role for tumor-associated stroma. Cancer research 2006, 66:632-637.

22. Leslie KO, Mitchell JJ, Woodcock-Mitchell JL, Low RB: Alpha smooth muscle actin expression in developing and adult human lung. Differentiation 1990, 44:143-149.

23. Satelli A, Li S: Vimentin in cancer and its potential as a molecular target for cancer therapy. Cell Mol Life Sci 2011, 68:3033-3046. 
24. Ivaska J: Vimentin central hub in EMT induction. Small GTPases 2011, 2:51-53.

25. Mendez MG, Kojima S, Goldman RD: Vimentin induces changes in cell shape, motility, and adhesion during the epithelial to mesenchymal transition. FASEB J 2010, 24:1838-1851.

26. Giarnieri E, De Vitis C, Noto A, Roscilli G, Salerno G, Mariotta S, Ricci A Bruno P, Russo G, Laurenzi A, Giovagnoli MR, Ciliberto G, Mancini R: EMT markers in lung adenocarcinoma pleural effusion spheroid cells. J Cell Physiol 2013, 228:1720-1726.

27. Thiery JP: Epithelial-mesenchymal transitions in development and pathologies. Curr Opin Cell Biol 2003, 15:740-746.

28. Liu D, Huang C-I, Kameyama K, Hayashi E, Yamauchi A, Kobayashi S, Yokomise $\mathrm{H}$ : E-cadherin expression associated with differentiation and prognosis in patients with non-small cell. Ann Thorac Surg 2001, 71:949-954.

29. Frixen UH, Behrens J, Sachs M, Eberle G, Voss B, Warda A, Ltehner D, Bircluneier W: E-cadherin-mediated cell-cell adhesion prevents invasiveness of human carcinoma cells. J Cell Biol 1991, 113:173-185.

30. Kosacka M, Jankowska R: Comparison of cytokeratin 19 expression in tumor tissue and serum CYFRA 21-1 levels in non-small cell lung cancer. Pol Arch Med Wewn 2009, 119:33-37.

31. Pang L, Wang J, Jiang Y, Chen L: Decreased levels of serum cytokeratin 19 fragment CYFRA 21-1 predict objective response to chemotherapy in patients with non-small cell lung cancer. Exp Therapeut Med 2013, 6:355-360.

32. Lee S, Lee CY, Kim DJ, Hong DJ, Lee JG, Chung KY: Pathologic correlation of serum carcinoembryonic antigen and cytokeratin 19 fragment in resected nonsmall cell lung cancer. Korean J Thorac Cardiovasc Surg 2013, 46:192-196.

33. Chyczewski L, Niklinski J, Chyczewska E, Laudanski J, Furman M: Immunohistochemical analysis of tissue localization of cytokeratin 19 in lung cancer. Rocz Akad Med Bialymst 1997, 42(Suppl 1):162-172.

34. Jung M, Kim SH, Hong S, Kang YA, Kim SK, Chang J, Rha SY, Kim JH, Kim DJ, Cho BC: Prognostic and predictive value of carcinoembryonic antigen and cytokeratin-19 fragments levels in advanced non-small cell lung cancer patients treated with gefitinib or erlotinib. Yonsei Med J 2012, 53:931-939.

35. Kosacka M, Jankowska R: The prognostic value of cytokeratin 19 expression in non-small cell lung cancer. Pneumonol Alergol Pol 2007, 75:317-323.

36. Masszi A, Di Ciano C, Sirokmany G, Arthur WT, Rotstein OD, Wang J, McCulloch CA, Rosivall L, Mucsi I, Kapus A: Central role for Rho in TGFbeta1-induced alpha-smooth muscle actin expression during epithelialmesenchymal transition. Am J Physiol Renal Physiol 2003, 284:F911-F924.

37. Zavadil J, Bottinger EP: TGF-beta and epithelial-to-mesenchymal transitions. Oncogene 2005, 24:5764-5774.

38. Katsuno Y, Lamouille S, Derynck R: TGF-beta signaling and epithelialmesenchymal transition in cancer progression. Curr Opin Oncol 2013, 25:76-84.

39. Willis BC, Borok Z: TGF- $\beta$-induced EMT: mechanisms and implications for fibrotic lung disease. Am J Physiol Lung Cell Mol Physiol 2007, 293:525-534.

40. Thomson S, Buck E, Petti F, Griffin G, Brown E, Ramnarine N, Iwata KK, Gibson N, Haley JD: Epithelial to mesenchymal transition is a determinant of sensitivity of non-small-cell lung carcinoma cell lines and xenografts to epidermal growth factor receptor inhibition. Cancer Res 2005, 65:9455-9462.

41. Ronnov-Jessen L, Petersen OW: Induction of alpha-smooth muscle actin by transforming growth factor-beta 1 in quiescent human breast gland fibroblasts: implications for myofibroblast generation in breast neoplasia. Lab Invest 1993, 68:696-707.

42. Kang Y, Massague J: Epithelial-mesenchymal transitions: twist in development and metastasis. Cell 2004, 118:277-279.

43. Pozharskaya V, Torres-Gonzalez E, Rojas M, Gal A, Amin M, Dollard S, Roman J, Stecenko AA, Mora AL: Twist: a regulator of epithelial-mesenchymal transition in lung fibrosis. PLoS One 2009, 4:e7559.

44. Wang G, Dong W, Shen H, Mu X, Li Z, Lin X, Liu Y, Du J: A comparison of twist and E-cadherin protein expression in primary non-small-cell lung carcinoma and corresponding metastases. Eur J Cardiothorac Surg 2011, 39:1028-1032.

45. Grivennikov SI, Greten FR, Karin M: Immunity, inflammation, and cancer. Cell 2010, 140:883-899.
46. Huber MA, Kraut N, Park JE, Schubert RD, Rettig WJ, Peter RU, Garin-Chesaw P: Fibroblast activation protein differential expression and serine protease activity in reactive stromal fibroblasts of melanocytic skin tumors. J Invest Dermatol 2003, 120:182-188.

47. Cerfolio RJ, Allen MS, Nascimento AG, Deschamps C, Trastek VF, Miller DL, Pairolero PC: Inflammatory pseudotumors of the lung. Ann Thorac Surg 1999, 67:933-936.

48. Morinaga S, Shimosato $Y$ : Pathology of the microadenocarcinoma in theperiphery of the lung. Pathol Clin Med Jpn 1987, 5:74-80.

49. Weng SY, Tsuchiya E, Kasuga $\mathrm{T}$, Sugano H: Incidence of atypical bronchioloalveolar cell hyperplasia of the lung: relation to histological subtypes of lung cancer. Virchows Arch 1992, 420:463-471.

50. Chapman AD, Kerr KM: The association between atypical adenomatous hyperplasia and primary lung cancer. Br J Cancer 2000, 5:632-636.

51. Aoyagi Y, Yokose T, Minami Y, Ochiai A, lijima T, Morishita Y, Oda T, Fukao K, Noguchi M: Accumulation of losses of heterozygosity and multistep carcinogenesis in pulmonary adenocarcinoma. Cancer Res 2001, 61:7950-7954.

doi:10.1186/s13019-014-0147-z

Cite this article as: Du et al.: Fibroblast phenotypes in different lung diseases. Journal of Cardiothoracic Surgery 2014 9:147.

\section{Submit your next manuscript to BioMed Central and take full advantage of:}

- Convenient online submission

- Thorough peer review

- No space constraints or color figure charges

- Immediate publication on acceptance

- Inclusion in PubMed, CAS, Scopus and Google Scholar

- Research which is freely available for redistribution

Submit your manuscript at www.biomedcentral.com/submit
C) Biomed Central 